\title{
Dogmas, Mitos y Postulados en la Reforma Universitaria
}

\author{
Por Augusto Salazar Bondy
}

La crisis universitaria, esa situación de inestabilidad de los organismos y las formas de acción que deriva.de la vacilación de los fundamentos en los que se asientan las instituciones universitarias; y el proceso de la Reforma, como desenvolvimiento en el tiempo de los esfuerzos encaminados a renovar la vida académica, han visto surgir y actuar tres formas principales de conciencia humana, la dogmática, la mítica y la racional. Ellas han dado su fisonomía peculiar a los conflictos y las luchas de los últimos decenios y es por eso que importa determinarlas bien y tenerlas presentes ab enjuiciar los acontecimientos universitarios. Aunque dan origen a tipos de actitud y modos de acción que emergen $y$ prevalecen en momentos sucesivos, dentro del ambiente académico, su influencia se extiende más allá de los períodos de hegemonía de una $u$ otra, y hace de ellas factores activos hasta nuestros días.

La conciencia dogmática es siempre un producto terminal, una manera de ver y de actuar que resulta de la decantación de actitudes que tuvieron en un momento su fuerza, su lozanía y su poder creador. Por ella, algo que decae, algo que está en trance de morir se aferra a la existencia, y sin energía ya para dar respuestas nuevas a situaciones nuevas, sin capacidad de adaptación transformadora, se crispa en ademán defensivo, se acora$z a$, cerrándose al mundo. En las religiones, en las doctrinas de todo tipo, como en las ciencias y las instituciones, la aparición de los dogmas señala el fin del impulso creador y el comienzo de la decadencia. La conciencia dogmática es la conciencia de la de- 
cadencia. Los dogmas se imponen cuando los individuos, los grupos o las entidades no son animados ya por el impulso original que los llevó alguna vez a abrir el camino del progreso y a labrarse así una personalidad neta y rica en sustancia; cuando no reciben positivamente las incitaciones del medio, ni se aplican $a$ transformarlo y a transformarse a sí mismos de manera adecuada y contínua. Entonces viven sólo de fórmulas gastadas, de ideas recibidas, de verdades que la autoridad impone, sin explicación ni prueba, y se mueven según la rutina de los moldes tradicionales. Impera así la tradición convertida en tierra yerma. Con ella, pasan al primer plano de la conciencia los prejuicios y la miopía intelectual que los nutre, el afón de conservar lo adquirido, el temeroso cuidado de los privilegios, la defensa de esos intereses que no son ya creadores, sino simplemente creados, es decir, todas las formas de la mezquindad y de la usura que definen la vida cerrada e improductiva.

La mentalidad dogmática, con su actitud de conservación y rechazo, ha imperado por largo tiempo en la Universidad peruana y no ha dejado aún enteramente de tener vigencia en ella. Esa mentalidad encarna la decadencia en la Universidad, y es testimonio de que algo muere irremisiblemente en la vida académica. La impermeabilidad a las fuerzas activas de la sociedad moderna, la indiferencia frente a los problemas que afectan a la realidad del país, el ciego mantenimiento de formas de organización envejecidas y estériles, que todavía podemos observar todavía a nuestro alrededor, denuncian la persistencia de los modos de una conciencia que aún está presa en las redes dogmáticas y cuya única forma de acción es la negativa. Niega tratando de convencer, es decir, fabricando justificaciones para convertir a su causa perdida a quienes confían en la renovación, para reducirlos a los viejos moldes y neutralizarlos finalmente. Cuando las justificaciones mentidas muestran su vaciedad, cuando la eficacia de los argumentos se hace ilusoria, recurre a otras formas de la negación: al compromiso que corrompe, a la intimidación o a la violencia. Los dogmas son las justificaciones pretendidas; son también la palabra santa destinada a ocultar y cohonestar el torpe recurso a la fuerza.

¿Qué dicen los dogmas que la vieja conciencia universitaria trataba de imponer? Que en la Universidad, como en todos los órdenes de la vida colectiva, la autoridad debe ser acatada y respetada, sean cuales fueren sus actos, sus fines reales y su 
procedencia. Toda oposición a ella y a su ley es rebeldía que atenta contra el principio jerárquico, garantía de la estabilidad y el desarrollo normal de las instituciones académicas. Por ello, la participación conjunta de los sectores que forman la comunidad universitaria en la conducción de la marcha institucional, el derecho de fiscalización, la libertad de crítica, y la asociación libre deben ser rechazadas, pues son sólo manifestaciones de una mentalidad disociadora que, como en la sociedad, en la Universidad no puede producir sino el desquiciamiento de las instituciones. Al igual que las autoridades, y en sus planos correspondientes, rígidamente jerarquizados, los catedráticos deben ser acatados y obedecidos, sean cuales fueren sus procedimientos, sus méritos y su conducta pública y privada. Así reza el dogma de la autoridad y la jerarquía.

Hay también un dogma de la tradición. Según él, la Universidad es una institución tradicional en su esencia, sostenida y animada por un espíritu asentado en el pasado y por doctrinas secularmente probadas. La más firme e imperativa misión universitaria no puede ser entonces sino la defensa de ese espíritu, suma de los beneficios de la civilización en que todos nos hemos criado, contra la acción de las fuerzas oscuras de la anarquía y el desorden que amenazan destruír el legado tradicional y con él la sociedad humana. Hay por eso opiniones e ideas que deben ser proscritas de la Universidad. En su recinto, como fuera de él, la libertad intelectual no puede laceptarse sino con scondiciones, justamente con aquellas favorables a la conservación de la herencia espiritual que se defiende.

La autonomía ha dado nacimiento también a un dogma. El más sutil y especioso de todos, porque utiliza un principio que corresponde a la verdadera esencia de la Universidad. Ese dogma se filtra inclusive en nuestro lenguaje cotidiano, como secuela de las ideas recibidas en que, sin pensarlo, nos apoyamos. Está en funciones, por ejemplo, cuando llamamos a San Marcos, indiferentemente, la Universidad o El Claustro. Como herencia de la conciencia dogmática, damos curso así a la idea de la Universidad enclaustrada, de la Universidad isla o reducto extraño al país. Psicoanalizando nuestra conciencia universitaria, encontramos, pues, tras nuestro lenguaje cotidiano, gravitando con todo el peso de los dogmas, el concepto de una autonomía falsamente interpretada como divorcio del país, como indiferencia de la Universidad frente a los problemas vitales de la nación, como 
refugio, como Olimpo del saber puro que repugna de toda contaminación práctica y de todo contacto con las impurezas de la acción social. Para este dogma, en suma, la casa de los doctores del saber sin tiempo y sin lugar, rodeada por el cordón de seguridad de su ley, tiene así, desde siempre, su estructura adecuada a las tareas propias del espíritu y no necesita sujetar sus órganos a las transformaciones que la historia concreta produce en la sociedad que la envuelve.

El dogma de la elite, que entrega la Universidad al uso de una minoría selecta, corona el cuadro de las principales actitudes negativas de la mentalidad dogmática. Imponiendo artificialmente un criterio de selección que no había sido determinado de acuerdo con las necesidades y el ritmo de la evolución del país, este dogma no significa de hecho sino el vano intento de cerrar la Universidad a las fuerzas sociales emergentes en la nación, para hacer de ella un reducto de los privilegiados de la fortuna con el monopolio de los beneficios de la cultura superior.

Por la afirmación exclusiva y extrema del principio de autoridad, del sentido tradicional de la cultura universitaria, del aislamiento institucional y del criterio de elite, la mentalidad dogmática se opuso tenazmente, y se opone todavía en sus remanentes, a toda reforma de la Universidad. Para ella, que representa un mundo en derrota, la alternativa en la Universidad es también resistir o perecer. Por eso conjuga o alterna dogmas y violencias, declaraciones mentidas e imposiciones.n Aela Qverdad deformada y a la fuerza, apela porque no es capaz ya de adecuar sus reflejos arcaicos a los nuevos estímulos; porque ha quedado reducida a puros mecanismos de defensa; porque en su ciego afán de conservación, ha perdido contacto con las fuentes de su propia vida: las energías, las inquietudes, los ideales de los hombres del país en que, sin reconocerlo, se apoya.

Frente a esta conciencia decadente, la reforma universitaria emerge por el impulso de una conciencia de signo contrario: la conciencia mítica, el espíritu del orto y de los alumbramientos. Al dogma frío y calculador se enfrenta el mito pleno de calor juvenil y de resonancias ideales. La actitud mítica es la de la rebeldía, la que rompe las barreras y abre los caminos del futuro. Por amor al fuiuro, niega en bloque las realidades presentes y aspira a construír todo desde sus cimientos, sin detenerse a pensar en posibilidades y medios, sin pasar por la criba del juicio los elementos con los que trabaja, para separar los valores au- 
ténticos de los ideales hechizos. Como no discrimina críticamente, como no matiza ni gradúa, opera con verdades sumarias y rechazos tajantes, reflejos de las simpatías espontáneas, las pasiones, los presentimientos de realidades mejores que la nutren. Su sustancia es por eso el sentimiento, ese ímpetu vital que lanza al joven, sin armas, al combate, electrizado por la contemplación de los ideales que piden ser realizados.

En las luchas sociales, políticas o religiosas, esta proyección idealizadora de la conciencia mítica es la que ha abierto las brechas de la historia y ha hecho posible construír, en la tierra conquistada, con el aporte de energías frescas, mejores formas de vida colectiva. Así también, en la Universidad, los mitos de la reforma universitaria son los que han hecho batirse en retirada a la vieja mentalidad. Porque se alimentan del fondo ético que guardan las verdaderas rebeldías, estos mitos contienen todo lo bueno que hay en el ideal de la Reforma, sus más puras aspiraciones y valores de perfección. Porque son productos de una conciencia joven, han puesto en juego energías lozanas capaces de soportar por largo tiempo un movimiento de transformación. La conciencia mítica, que es predominantemente afectiva e impulsiva, y no racional y crítica, sabe de fines generales pero no- de medios y metas inmediatas, no tiene disposición selectiva, y por eso se pierde muchas veces en acciones sin efecto práctico. Forjada como ha sido en la lucha, en la reacción contra las limitaciones y los abusos del dogmatismo, es proclive también a las negaciones extremas. La actitud mítica sirve así más para destruír, que es quehacer de impulso y entrega, que para planear y construír, que es tarea de reflexión y paciencia.

Cuando las actitudes dogmáticas ya no valen siquiera como medios defensivos, porque la batalla está ganada por el espíritu de reforma, y la conciencia mítica ha cumplido su misión de limpieza y remozamiento, se acerca la hora de edificar. Hay que volver entonces sobre los mitos, considerarlos sin apasionamiento, liberarlos de los elementos que los lastran y dejar que, por encima de los rechazos y las simplificaciones circunstanciales, operen con su savia nueva los auténticos valores que encierran.

Para ello, es preciso darse cuenta cabal de su carácter reactivo, de los motivos que, a su hora y en su ambiente, justificaron las negaciones extremas de la conciencia mítica. Así, sin la presencia y la acción del dogma de la autoridad y la jerarquía, no es posible comprender el mito de la autoridad sospechosa por 
esencia, el llamado a la rebeldía permanente contra la ley, sin la base real, económica y social del dogmatismo, se escapa el sentido de la transposición emocional de la lucha de clases al ambiente universitario, que sanciona un divorcio definitivo entre los intereses de los profesores y los estudiantes; sin la violencia de la autoridad y del régimen que ella representaba no es comprensible la intención libertaria escondida tras la violencia de la tacha o la huelga y sólo en contraste con las armas vedadas que empleaba la disciplina autoritaria se nos hace clara y aceptable la idea del sindicato de estudiantes como organismo de lucha $\mathrm{y}$ el co-gobierno interpretado como conquista política.

De igual manera ocurre con los demás mitos. La idea de la Universidad sustentada en el espíritu tradicional, afirmada e impuesta como dogma, encontró su respuesta en el mito de la Universidad recreada desde sus cimientos. El impulso renovador pedía la liquidación total y simultánea de la Universidad antigua y de la tradición espiritual como único medio efectivo de reformar la vida académica. Con las estructuras institucionales y los contenidos de la cultura histórica debían cambiar también radicalmente los hombres. No cabía concebir la Reforma como un proceso en que podían coexistir los saltos y las evoluciones graduales, la creación al lado de la adaptación y el reajuste. La Reforma era creación desde la nada o no era. Tampoco en los hombres cabían mediaciones. Ser reformistas era asunto de destino o de conversión salvalora. La mi mologia dè la Reforma creó así su mesianismo, con sus profetas y sus elegidos, los únicos poseedores de la clave de la renovación, frente a quienes estaban todos los demás, los réprobos.

Al dogma de la Universidad enclaustradia y' aislada del país, respondió el mito de la Universidad copia fiel del país. Según él, la Universidad no posee una personalidad original, ni implica formas de acción, tareas, propósitos y fines peculiares y diferenciales. De allí que los problemas de la Universidad, remedo de los de la nación, no puedan solucionarse sino por el empleo de los mismos medios y por acción de las mismas fuerzas que operan en las luchas sociales, económicas y políticas. Reducidos a su esencia, el combate reformista, sus ideales y sus armas no son sino políticos. No hay problemas y criterios universitarios y extrauniversitarios, hay sólo política fuera y dentro de la Universidad. 
Frente al imperio y al orden del privilegio que, embozadamente, defendía el dogma de la elite, los mitos reformistas exaltaron la democratización de la enseñanza y la franquía irrestricta del acceso a la Universidad. Enseñoréandose de la actitud mítica, la desconfianza, que impregna también la mentalidad dogmática, hizo preferible al reformista pecar de liberalidad antes que dar pábulo a las maniobras discriminatorias de los representantes de la Universidad antigua. Era una desconfianza de signo contrario, es cierto, porque se alimentaba de idealidad y no de egoísmo; pero justamente porque apuntaba a las metas más altas, descuidaba la vigilancia de lo inmediato, no acertaba a encontrar los medios seguros para construír o proponía paliativos en vez de remedios eficaces. Por recelo y por vehemencia multiplicaba las fórmulas de solución, confiándose a recetas que, aunque orladas del prestigio afectivo del mito, no resolvían los problemas sino que los suponían resueltos por una previa Reforma- y transformación de- la Universidad. Hoy, por ejemplo, después de varios años de aplicación de la asistencia libre, sabemos bien que ella no resuelve nada o es, en todo caso, un paliativo que supone otros defectos vigentes. Pero la asistencia libre tuvo su mito, como la cátedra paralela y otras fórmulas reformistas, por las cuales buscaba hacerse objetivo el ideal de la democratización de la Universidad.

Superando a la conciencia mítica, cancelando definitivamente a la conciencia dogmáticacilaefeforma universitaria exige la actuación de otra mentalidad, la que informa una conciencia racional aplicada a la realidad. Una conciencia que no imponga dogmas, ni exalte mitos, sino que proponga postulados. En el dominio de la ciencia y en el de la moralidad, el postulado representa un principio que norma el desenvolvimiento del pensamiento y la acción, una pauta intelectual que, adecuándose a la naturaleza de las cosas y de las situaciones, encamina y respalda el conocimiento y la conducta. Operando como puentes entre la razón y la realidad, los postulados ganan su validez de la correspondencia con la esencia de los objetos y de la fecundidad que revele su aplicación.

Si el saber científico es la fuente matriz de la verdadera vida universitaria ¿no es tiempo ya de que la transformación de la Universidad encuentre sus propios moldes científicos y sea presidida por la vigencia de una conciencia crítica y realista? Con 
su actuación no pueden sino ganar los mitos que han servido de levadura al proceso reformista, porque su vocación genuina es la de la realidad, y realizarlos puede sólo una conciencia que los asuma y los integre en el juego de las fuerzas reales.

La nueva mentalidad no se siente presa en el dilema: autoridad o rebeldía, porque en la Universidad, como en la sociedad, no reconoce jerarquías inmutables ni poderes que no emanen del libre consentimiento de las personas, y porque considera engañosa y artificial, cuando ha cambiado la composición social de la Universidad, la interpretación de los conflictos universitarios en términos de lucha de clases. Frente a estas posiciones antagónicas, el postulado que debe guiarnos es la idea de la Universidad como corporación democrática, fundada en la comunidad de los fines, la solidaridad de los sentimientos, la identidad de las responsabilidades ante la nación y la confianza y el respeto mutuos de todos sus miembros, catedráticos, alumnos y graduados. Para esta noción rectora de la Universidad, la autoridad no implica violencia, porque la soberanía institucional reside en el cuerpo colectivo; el gobierno de la institución no es exclusiva de nadie, sino que compete por derecho a todos los miembros de la comunidad; la jerarquía no puede ser aceptada como un orden rígido y definitivo, sino como un mecanismo flexible fundado en la neecesidad de distribuír tareas y compartir responsabilidades; la disciplina debe ser sólo la manifestación exterior de la espontánea convergencia de los esfuerzos hacia metas comunes; y la libertad de opinión y crítica no contradice sino que coadyuva a la vigorización del espíritu comunitario.

El concepto de la Universidad como institución nacional constituye el núcleo del postulado que norma las relaciones de la comunidad universitaria con el Estado y la Nación. La Universidad no es una isla en el país, ni un claustro divorciado del mundo. No por eso deja de tener una personalidad propia, una manera peculiar de ser nacional. Este postulado no cierra pues los ojos a la evidencia de que la realidad universitaria está condicionada por las estructuras sociales y económicas del país, sino que trabaja a partir de ella; asume que muchos de sus problemas no hacen sino reflejar los problemas más generales que afectan al país, y que el atraso de la Universidad y las posibilidades de superarlo están ligados al atraso y a las posibilidades de desarrollo de la nación. Pero no olvida tampoco que no hay aquí 
una determinación férrea que comprenda a todos los elementos de la realidad universitaria por igual, sino grados de determinación o un condicionamiento global, estadístico diríamos, que aquí y allá permite excepciones y diferenciaciones y que deja en libertad fuerzas capaces de iniciar, desde el ambiente universitario, procesos que repercutan en el país o promuevan cambios nacionales. La Universidad y el país no son independientes: sus destinos son solidarios. Pero los lazos que los unen no forman un círculo cerrado, sin salida para la espontaneidad; forman más bien un espiral que permite mutuas acciones y reacciones constantes y en niveles cada vez diferentes. Esta originalidad relativa de la existencia universitaria da derecho a hablar de cuestiones, soluciones, normas y tareas específicamente universitarias. Más por ser relativa y no absoluta, cancela definitivamente las ilusiones de independencia. La autonomía no puede ser pues pretexto para el divorcio de la Universidad y el país. Más aun, de la acción espontánea y creadora que corresponde por derecho a la Universidad y que es el fundamento de la verdadera autonomía, se deriva la responsabilidad que la institución tiene frente al país, de cuyo desarrollo y ascenso gradual de nivel puede ser ella órgano rector. Este postulado de la autonomía responsable ante la nación descalifica así igualmente la actitud de indiferencia que juzga los problemas peruanos, y en general los sociales y políticos que comprometen la vida nacional, como ajenos a la institución n la conformistà i $y$ resignada que espera las soluciones venidas de fuera, y la meramente política que confía en resolver los problemas universitarios con procedimientos que no alcanzan a tocar su esencia.

El postulado que define la esencia de la tarea universitaria viene a complementar a los anteriores. Según él, la Universidad es una institución de enseñanza, de investigación y de educación humana. Su misión propia y fundamental es en consecuencia la de conservar la cultura humana, con sus elementos tradicionales y revolucionarios; transmitirla con la mayor eficacia posible y darle la máxima difusión; acrecentarla, es decir, hacer de ella, por el trabajo de la investigación original, no un producto de museo, cuyo lugar propio es el pasado, sino una fuente constante de progreso y de bienestar; y forjar hombres por el trabajo de la ciencia, en la disciplina de la reflexión racional proyectada a todos los horizontes del mundo, por la meditación social y el 
trato con la historia, que enseñan la tolerancia con todas las opiniones y todas las doctrinas y el culto de la libertad; y por el cultivo de la sensibilidad artística que abre la conciencia a las idealidades creadoras.- Forjar hombres responsables, maduros clarividentes, imbuídos de una misión de progreso nacional sin provincianismos ni veleidades cosmopolitas, bien enraízados en su historia pero también saturados del sentido ético de la dignidad de todos los hombres.

Pero esta Universidad debe ser para todos, es decir, debe estar al alcance de cualquiera que tenga la capacidad y la disposición para asumir la árdua tarea de construír la cultura superior del país. Porque el destino de la nación está en juego con el progreso de la Universidad, no caben en ella discriminaciones artificiosas o interesadas. El criterio de la selección universitaria debe ser, sin excepciones, el de la aptitud; un criterio, además, objetivo y abierto, que no se someta a una norma ciega no probada en la realidad, sino que tome en cuenta las variedades, los tipos, los grados y las escalas de formación exigidos por las necesidades del país y que a ellos adecúe los servicios en los que se canaliza la actividad académica. La conciencia racional postula así una selección universitaria, democrática en su inspiración y adecuada paso a paso a las exigencias del país; opuesta a la vigencia del concepto de elite de clase y apta, al mismo tíempo, para superar y corregir los excesos del mito del libre acceso, que no sólo desmedran a la Universidad sino que restan al país esfuerzos útiles en otros campos igualmente productivos y necesarios al bienestar nacional.

Los postulados, hemos dicho, muestran su validez por su adecuación a la naturaleza de las cosas y por la fecundidad de su aplicación. Frente a ellos no cabe otra actitud que la de buscar en los hechos su eficacia y comprobar en la práctica si se adecúan a la esencia de las cosas. Aplicándolos, debemos averiguar a través del quehacer que se orienta por ellos si potencian dinámicamente la esencia de la Universidad y recogen los mejores ideales de progreso que el movimiento de la Reforma universitcria proclamó al surgir. Pero su aplicación supone el trabajo científico, la experimentación paciente, la selección y la prueba de los procedimientos, y la información objetiva sin la cual no hay orientación adecuada posible. Los postulados son ideas rectoras. Aquello que van a regir son los esfuerzos universitarios que de- 
ben cumplir todas las exigencias de la conciencia científica y técnica para ser esfuerzos verdaderamente racionales. Tenemos por delante la tarea de hacer vida universitaria. Guiados por los postulados de una razón realista, vigilantes, para que el trabajo no se detenga, y empeñosos, para que siga adelante, todos debemos contribuir a la transformación de la Universidad. Esta tarea será de continuación indefinida de la Reforma Universitaria. 